\title{
Two Dabigatran Fast Reversals in a 4-month Period - a Case Report
}

\author{
Vítor Fagundes, Mari Mesquita \\ Internal Medicine, Centro Hospitalar do Tâmega e Sousa (CHTS), EPE, Penafiel, Portugal \\ Doi: 10.12890/2019_001311 - European Journal of Case Reports in Internal Medicine - ๑ EFIM 2019
}

Received: 03/10/2019

Accepted: 08/10/2019

Published: 04/12/2019

How to cite this article: Fagundes V, Mesquita M. Two dabigatran fast reversals in a 4-month period - a case report. EJCRIM 2019;6: doi:10.12890/2019_001311.

Conflicts of Interests: The Authors declare that there are no competing interest

This article is licensed under a Commons Attribution Non-Commercial 4.0 License

\begin{abstract}
Introduction: Idarucizumab is available for immediate reversal of dabigatran-induced anticoagulation in life-threatening bleeding or urgent surgery in patients with non-valvular atrial fibrillation (nvAF).

Case description: We report a case of an 85-year-old female treated with dabigatran for nvAF, submitted to two fast reversal procedures with idarucizumab in a 4-month period. In the first emergency episode, the patient was admitted due to a fall-related cerebral haemorrhage and subdural haematoma. There was a fast reversal of the effects of dabigatran after idarucizumab administration, which allowed stoppage of the bleeding and a decrease in intracranial pressure, with full patient recovery. Four months later, the patient revisited the hospital complaining of diffuse abdominal pain while on the same antithrombotic therapy. Physical examination showed signs of peritoneal irritation and the use of idarucizumab to reverse the effects of dabigatran was decided upon to secure normal bleeding conditions before surgery. Discussion: Idarucizumab is an efficient, safe and feasible option for dabigatran-treated nvAF patients, when urgent anticoagulant effect reversal is needed.
\end{abstract}

\section{LEARNING POINTS}

- Clinical situations requiring urgent reversal of the anticoagulant effects of non-vitamin $\mathrm{K}$ antagonist oral anticoagulants are expected to be relatively rare but the existence of antidotes enables the clinical management of these situations.

- Even in independent urgent circumstances occurring over a short period of time, the repeated use of idarucizumab promptly and safely reverses the dabigatran anticoagulant effect without compromising the patient's clinical outcome.

- The development and implementation of specific anticoagulation reversal protocols and better guidance on using baseline coagulation tests are needed to ensure timely and appropriate use of this new therapeutic option.

\section{KEYWORDS}

Atrial fibrillation, dabigatran, fast reversal, idarucizumab, urgent procedure

\section{INTRODUCTION}

Non-vitamin K antagonist oral anticoagulants (NOACs) are widely used in the prevention and treatment of stroke and thromboembolic events in patients with non-valvular atrial fibrillation (nvAF) ${ }^{[1]}$.

The NOAC dabigatran etexilate is increasingly being used due to its demonstrated favourable risk-benefit profile, and also, because it was the first anticoagulant to have an approved specific reversal agent, the humanized monoclonal antibody fragment idarucizumab ${ }^{[2]}$. With a binding affinity approximately 300-fold more potent than dabigatran's binding affinity for thrombin, it is indicated in adult patients when rapid reversal of the dabigatran anticoagulant effect is required for an emergency surgery/urgent procedure and in life-threatening or uncontrolled bleeding circumstances ${ }^{[3,4]}$. Despite the results from clinical trials, where reversal effects were evident almost immediately after administration ${ }^{[4]}$, information on the use of idarucizumab in the clinical setting remains limited. 


\section{CASE DESCRIPTION}

On July 2016, an 85-year-old female patient was admitted to the emergency department due to a fall-related cerebral haemorrhage and subdural haematoma.

The patient was under anticoagulation therapy with dabigatran $110 \mathrm{mg}$ due to nvAF since 2013. Past medical history included dyslipidaemia, treated with simvastatin $40 \mathrm{mg}$, and hypertension, treated with perindopril $5 \mathrm{mg}$ and nebivolol $5 \mathrm{mg}$. For gastric protection, the patient was prescribed omeprazole $20 \mathrm{mg}$.

On physical examination, the patient was alert and oriented. Blood pressure (BP) was 130/80 $\mathrm{mmHg}$, heart rate 72 beats/min and oxygen saturation 98\%; temperature and pulmonary auscultation were normal. The patient presented 15 points on the Glasgow Coma Scale and the blood analysis showed an unaltered haemogram and renal function.

A brain computed tomography (CT) scan showed a subdural haematoma as a result of the head trauma. A fast reversal of the effects of dabigatran was required to stop the bleeding and decrease the intracranial pressure.

According to the patient, the last dose of dabigatran was taken at 8:00h of that day. After the administration of $5 \mathrm{~g}(2 \times 2.5 \mathrm{~g} / 50 \mathrm{ml})$ idarucizumab, there was a reversal of the coagulation markers (Table 1). Bleeding was controlled, the patient clinical situation remained stable, and anticoagulation was restarted after resorption of the subdural haematoma.

Four months later, on November 2016, the same patient was admitted to the emergency department due to diffuse abdominal pain.

Physical examination showed signs of peritoneal irritation, BP was $114 / 54 \mathrm{mmHg}$, heart rate 70 beats/min, oxygen saturation $96 \%$, temperature $37.1^{\circ} \mathrm{C}$ and pulmonary auscultation was normal. The medication was the same as before.

An abdominal CT scan revealed intestinal occlusion with surgical indication, and again, an urgent need to reverse the effects of dabigatran. The patient's coagulation parameters were successfully reversed after the administration of $5 \mathrm{~g}(2 \times 2.5 \mathrm{~g} / 50 \mathrm{ml})$ idarucizumab, allowing the patient to be submitted to surgical treatment (Table 1).

Although no haemorrhagic complications occurred, the patient had a complicated post-operative period within the Intensive Care Unit, and died one month later.

\begin{tabular}{|c|c|c|c|c|c|}
\hline \multirow{4}{*}{ Clinical parameters } & \multirow{4}{*}{ Ref Values } & \multicolumn{4}{|c|}{ Hospital visits } \\
\hline & & \multirow{2}{*}{\multicolumn{2}{|c|}{$\begin{array}{l}\text { First episode } \\
20 / 07 / 2016\end{array}$}} & \multicolumn{2}{|c|}{ Second episode } \\
\hline & & & & \multirow{2}{*}{$\frac{26 / 11 / 2016}{22: 37 h}$} & \multirow{2}{*}{$\frac{27 / 11 / 2016}{01: 49 h}$} \\
\hline & & $20: 09 h$ & $23: 12 \mathrm{~h}$ & & \\
\hline \multicolumn{6}{|c|}{ THROMBOSIS AND HAEMOSTASIS } \\
\hline PT (sec) & - & 17.9 & 11.8 & 21.9 & 13.2 \\
\hline $\begin{array}{l}\text { PT Daily Normal } \\
\text { (sec) }\end{array}$ & - & 10.9 & 10.9 & 10.9 & 10.9 \\
\hline aPTT (sec) & - & 58.4 & 30.9 & 59.1 & 38.7 \\
\hline $\begin{array}{l}\text { aPTT Daily Normal } \\
\text { (sec) }\end{array}$ & - & 31.4 & 31.4 & 31.4 & 31.4 \\
\hline Ratio & - & 1.85 & 0.98 & 1.88 & 1.23 \\
\hline$T T(\mathrm{sec})$ & - & $>120.0$ & 16.1 & $>120.0$ & 18.9 \\
\hline $\begin{array}{l}\text { TT Daily Normal } \\
\text { (sec) }\end{array}$ & - & 14.8 & 14.8 & 14.8 & 14.5 \\
\hline Ratio & - & 1.00 & 1.09 & - & 1.28 \\
\hline $\begin{array}{l}\text { Fibrinogen } \\
\text { (mg/dL) }\end{array}$ & $200-400$ & 109 & 292 & - & - \\
\hline INR & - & 1.61 & 1.08 & 1.94 & 1.21 \\
\hline$d T T(n g / m L)$ & $\begin{array}{l}<30.0 \text { - negative } \\
\geq 30.0 \text { - positive }\end{array}$ & 420.1 & 1.1 & 363.1 & 0.9 \\
\hline
\end{tabular}

Table 1. Laboratory analyses: thrombosis and haemostasis.

PT - Prothrombin Time; aPTT - Activated Partial Thromboplastin Time; TT - Thrombin Time; dTT Dabigatran diluted Thrombin Time 


\section{DISCUSSION}

For more than 50 years, warfarin and other vitamin $\mathrm{K}$ antagonists (VKAs) were the only oral anticoagulants available for thromboembolic disease ${ }^{[1,2]}$. However, they require frequent monitoring and dose adjustments, carrying substantial risk and inconvenience ${ }^{[1,2]}$. With a favourable benefit-risk profile compared to VKAs, NOACs are presently the standard of care for stroke prevention in nvAF patients ${ }^{[1]}$.

Dabigatran has demonstrated efficacy and safety in several large clinical trials and observational studies, offering potential advantages over VKAs and fewer drug interactions ${ }^{[1]}$. However, due to the lack of a reliable reversible agent that allowed an effective management of patients in emergency situations, there was some reluctance to use it. With the approval of idarucizumab, which entirely reverses the dabigatran anticoagulant effects within minutes, this situation has been overcome ${ }^{[2-4]}$.

In the RE-VERSE AD trial, involving patients with life-threatening bleeding or who needed urgent invasive procedures, idarucizumab promptly reversed the effect of dabigatran ${ }^{[3]}$, corroborating its role in improving patient safety in a variety of situations requiring the rapid reversal of the anticoagulant effect. Moreover, idarucizumab has been associated with an effective haemeostasis in the setting of several emergency high-bleeding-risk surgeries or invasive procedures (see Appendix).

Nevertheless, clinical situations requiring urgent reversal of the anticoagulant effects of NOACs are expected to be relatively rare ${ }^{[1]}$. The incidence of major bleeding events is significantly reduced with NOACs compared to VKAs, and treatment discontinuation (along with supportive measures) are often sufficient, even in patients with moderate-to-severe bleeding ${ }^{[1,2]}$.

Despite the recommendation that emergency interventions or procedures should not be performed until at least $12 \mathrm{~h}$ (and ideally $24 \mathrm{~h}$ ) after the last NOAC dose intake, to reduce the risk of bleeding complication ${ }^{[1]}$, the reversal of the effects of dabigatran by idarucizumab was successful in the two independent emergency situations reported in our real-life clinical case.

In a Phase I study, an idarucizumab $5 \mathrm{~g}$ intravenous infusion was administered a second time to a subgroup of six healthy subjects to study the presence of anti-idarucizumab antibodies two months after the first administration. No idarucizumab antibodies were detected before the second administration, and afterwards they were only detected in one subject ${ }^{[5]}$. No impact on idarucizumab pharmacokinetics or reversal effects was observed, which makes it possible to predict that haemeostasis is effectively achieved without affecting patient safety in similar settings.

The specific roles of antidotes, when used with direct oral anticoagulants in reducing case fatality or improving the overall clinical course of these events, are not thoroughly understood. The development and implementation of specific anticoagulation reversal protocols and further knowledge of real-world-experience data are needed for the optimal reversal of dabigatran anticoagulation effects in emergency situations.

Our case report provides additional evidence regarding the efficiency, safety and feasibility of idarucizumab in the emergency setting for dabigatran-treated patients with nvAF when an urgent reversal is needed.

\section{REFERENCES}

1. Steffel J, Verhamme P, Potpara TS, Albaladejo P, Antz M, Desteghe L, et al; ESC Scientific Document Group. The 2018 European Heart Rhythm Association Practical Guide on the use of non-vitamin K antagonist oral anticoagulants in patients with atrial fibrillation. Eur Heart J 2018;39(16):1330-1393.

2. Milling TJ Jr, Ziebell CM. A review of reversal of oral anticoagulants, old and new, in major bleeding and the need for urgent surgery. Trends Cardiovasc Med 2019;pii:S1050-1738(19)30041-6. Epub 2019 Mar 26.

3. Pollack CV Jr, Reilly PA, van Ryn J, Eikelboom JW, Glund S, Bernstein RA, et al. Idarucizumab for dabigatran reversal - full cohort analysis. N Engl J Med 2017;377(5):431-441.

4. Cortese F, Calculli G, Gesualdo M, Cecere A, Zito A, De Vito F, et al. Idarucizumab: what should we know? Curr Drug Targets 2018;19(1):81-88.

5. Praxbind. Summary of product characteristics. Available from: https://www.ema.europa.eu/en/documents/product-information/praxbind-epar-product-information_en.pdf (accessed 24th September 2019). 
1. Agosti S, Casalino L, Rocci E, Zaccone G, Rota E. Successful intravenous thrombolysis for ischemic stroke after reversal of dabigatran anticoagulation with idarucizumab: a case report. J Med Case Rep 2017;11(1):224.

2. Alhashem HM, Avendano C, Hayes BD, Winters ME. Persistent life-threatening hemorrhage after administration of idarucizumab. Am J Emerg Med 2017;35(1):193.e3-193.e5.

3. Alvarez Bravo G, Orts Castro E, Carvalho Monteiro G, López Zuazo I. Intravenous fibrinolysis in ischemic stroke of large vessel after reversing effect of dabigatran with idarucizumab. J Stroke Cerebrovasc Dis 2017;26(9):e192-e193.

4. Arai N, Mine Y, Kagami H, Maruyama M, Daikoh A, Inaba M. Safe burr hole surgery for chronic subdural hematoma using dabigatran with idarucizumab. World Neurosurg 2018;109:432-435.

5. Belli EV, Lee T. Idarucizumab (Praxbind) for reversal of pradaxa prior to emergent repair of contained ruptured transverse arch aneurysm. Ann Card Anaesth 2017;20(3):369371.

6. Bereczki D Jr, Szilágyi G, Kakuk I, Szakács Z, May Z. [Administration of idarucizumab in spontaneous intracerebral hemorrhage under dabigatran-therapy]. Ideggyogy Sz 2017;70(9-10):349-353.

7. Berrouschot J, Stoll A, Hogh T, Eschenfelder CC. Intravenous thrombolysis with recombinant tissue-type plasminogen activator in a stroke patient receiving dabigatran anticoagulant after antagonization with idarucizumab. Stroke 2016;47(7):1936-1938.

8. Braemswig TB, Eschenfelder CC, Nolte CH. Emergency LP in a patient receiving dabigatran after antagonization with idarucizumab. Am J Emerg Med 2017;35(4):662.e3-662. e4.

9. Driesz L, Barabás É, Bodócs I, Szántó Z, Herr G, Bencsik G, et al. [The first use of iv. idarucizumab for dabigatran reversal in Hungary]. Orv Hetil 2017;158(10):387-392.

10. Dumps C, Halbeck E, Schimpf J, Forst H. [Perioperative coagulation management during ascending aorta replacement on apixaban]. Anaesthesist 2016;65(8):595-600.

11. Edwards G, Roman C, Jithoo R, Mitra B. Use of idarucizumab for dabigatran reversal: emergency department experience in two cases with subdural haematoma. Trauma Case Rep 2017;13:46-49.

12. Facchinetti R, DeGuidi G, Pitoni F, Ricci G, Lippi G. Rapid and well tolerated action of idarucizumab for antagonizing dabigatran in a patient needing urgent thrombolysis: a case report. Blood Coagul Fibrinolysis 2017;28(7):576-579.

13. Hegemann I, Ganter C, Widmer CC, Becker M, Müller D, Spahn DR. Ongoing redistribution of dabigatran necessitates repetitive application of idarucizumab. Br J Anaesth 2018;121(2):505-508.

14. Held V, Eisele P, Eschenfelder CC, Szabo K. Idarucizumab as antidote to intracerebral hemorrhage under treatment with dabigatran. Case Rep Neurol 2016;8(3):224-228.

15. Henderson RS Jr, Deshpande S, Williams B, Taylor BS, Tanaka KA. Idarucizumab for dabigatran reversal in emergency type-A aortic dissection. $J$ Cardiothorac Vasc Anesth 2017;31(6):e80-e81.

16. Hummel BA, Senger S, Schleicher C, Eichler H. [The use of idarucizumab in intracerebral bleeding - a case report]. Dtsch Med Wochenschr 2018;113(13):961-964

17. Intagliata NM, Maitland H, Pellitier S, Caldwell SH. Reversal of direct oral anticoagulants for liver transplantation in cirrhosis: a step forward. Liver Transpl 2017;23(3):396-397.

18. Izaguirre Ávila R, Bahena López JE, Cortina de la Rosa E, Hernández Márquez MÁ. Idarucizumab to revert the anticoagulant effect of dabigatran in traumatic acute subdural haematoma: a case report of first use in Latin America. Eur Heart J Case Rep 2019;3(2):ytz098.

19. Jóźwik A, Lisik W, Czerwiński J, Kosieradzki M. Simultaneous pancreas-kidney transplantation in a patient with heparin-induced thrombocytopenia on dabigatran therapy. Ann Transplant 2018;23:232-235.

20. Kafke W, Kraft P. Intravenous thrombolysis after reversal of dabigatran by idarucizumab: a case report. Case Rep Neurol 2016;8(2):140-144.

21. Lo WT, Ng KF, Chan SC, Kwok VW, Fong CS, Chan ST, et al. Intravenous stroke thrombolysis after reversal of dabigatran effect by idarucizumab: first reported case in Hong Kong. Hong Kong Med J 2018;24(1):81-83.

22. Mazur P, Darocha T, Filip G, Grudzień G, Drwiła R, Kapelak B. Idarucizumab for dabigatran reversal in patients with atrial fibrillation undergoing emergency surgery for acute aortic syndrome. Pol Arch Med Wewn 2016;126(7-8):579-581.

23. Mourafetis J, Doctor N Jr, Leung S. Treatment of gastrointestinal bleeding with idarucizumab in a patient receiving dabigatran. Am J Health Syst Pharm 2018;75(4):177-182.

24. Ohya Y, Makihara N, Wakisaka K, Morita T, Ago T, Kitazono T, et al. Thrombolytic therapy in severe cardioembolic stroke after reversal of dabigatran with idarucizumab: case report and literature review. J Stroke Cerebrovasc Dis. 2018;27(7):e128-e131.

25. Pásztor M, Bereczki D Jr, Szakács Z, May Z. [Systemic thrombolysis after the administration of idarucizumab in acute ischemic stroke]. Ideggyogy Sz 2017;70(7-8):284-288.

26. Peetermans M, Pollack C Jr, Reilly P, Liesenborghs L, Jacquemin M, Levy JH, et al. Idarucizumab for dabigatran overdose. Clin Toxicol (Phila) 2016;54(8):644-646.

27. Rimsans J, Rhoten M, Sylvester K, Singh SK, Connors JM. Idarucizumab for urgent reversal of dabigatran for heart transplant: a case report. Am J Hematol 2017;92(3):E34-E35.

28. Schäfer N, Müller A, Wüllner U. Systemic thrombolysis for ischemic stroke after antagonizing dabigatran with idarucizumab-a case report. J Stroke Cerebrovasc Dis 2016;25(8):e126-127.

29. Sheikh-Taha M. Idarucizumab for reversal of dabigatran: single-center real-world experience. Am J Cardiovasc Drugs 2019;19(1):59-64.

30. Tireli D, He J, Nordling MM, Wienecke T. Systemic thrombolysis in acute ischemic stroke after dabigatran etexilate reversal with idarucizumab-a case report. J Stroke Cerebrovasc Dis 2017;26(7):e123-e125.

31. Tomaszuk-Kazberuk A, Łopatowska P, Młodawska E, van Ryn J, Reilly PA, Pollack CV. Successful use of idarucizumab as a reversal agent for dabigatran in a patient with acute dissected aortic aneurysm. Pol Arch Intern Med. 2017;127(1):68-70.

32. Tralhão A, Aguiar C, Ferreira J, Rebocho MJ, Santos E, Martins D, et al. Dabigatran reversal with idarucizumab in a patient undergoing heart transplantation: first European report. Thromb J 2017;15:23.

33. Turine G, Peeters A, Hermans C, Eeckhoudt S, Duprez T. Intravenous thrombolysis after reversal of dabigatran by idarucizumab: a moment to be a pioneer. Acta Neurol Belg 2017;117(3):753-755.

34. Vosko MR, Bocksrucker C, Drwiła R, Dulíček P, Hauer T, Mutzenbach J, et al. Real-life experience with the specific reversal agent idarucizumab for the management of emergency situations in dabigatran-treated patients: a series of 11 cases. J Thromb Thrombolysis 2017;43(3):306-317. 